\title{
AOR
}

Selected Papers of \#AolR2019:

The $20^{\text {th }}$ Annual Conference of the Association of Internet Researchers Brisbane, Australia / 2-5 October 2019

\section{COLLABORATIVE VIDEO LOGS: VIRTUAL COMMUNITIES OF PRACTICE AND ALIVENESS IN THE MUSIC CLASSROOM}

Christopher Cayari

Purdue University, West Lafayette, Indiana

\section{Online Learning and Community on YouTube}

Educational researchers have explored how YouTube and the practices of its users can be incorporated into the classroom. Hung's (2011) use of vlogs in an English for Specific Purposes undergraduate course revealed that vlogging allowed for reflection through visual representations, self-evaluation, professional development, and peer learning. Creating YouTube-inspired video activist documentaries in a Grade 8 classroom helped students develop a critical eye for news reporting, social awareness, and online media (Lin and Polaniecki, 2009). While practices associated with creation for the medium could be applied to the classroom, Juhasz (2008) found challenges when attempting to conduct an entire class on YouTube including publicly available lectures, class discussions, and homework responses. The students had to combat negative feedback from non-student YouTube users, and technical issues for students were troublesome and time consuming. My previous research has led to findings that suggested vlogging in small groups, or collaborative vlogs (CVLs), can lead to powerful social and educational outcomes that develop a community of learners who work together to construct knowledge and relationships (Cayari \& Fox, 2013; Fox \& Cayari, 2016). Wenger's (1998) social learning theory has been explored in online music learning contexts where communities of practice (CoPs) construct meaning, develop practices, form communities, and establish identity through virtual interactions (Waldron \& Veblen, 2009).

Within my classroom as a higher education instructor, I wanted to critically examine how CVLs could be used to develop CoPs by considering how asynchronous video smallgroup discussions developed what Wenger, McDermott, and Snyder (2002) describe as aliveness, a concept that often leads to vibrant, self-driven learning communities. The seven design principles of aliveness that could be applied to develop CoPs were:

Suggested Citation (APA): Cayari, Christopher. (2019, October 2-5). Collaborative video logs: Virtual communities of practice and aliveness in the music classroom. Paper presented at AoIR 2019: The 20 ${ }^{\text {th }}$ Annual Conference of the Association of Internet Researchers. Brisbane, Australia: AolR. Retrieved from http://spir.aoir.org. 
Design for evolution, open a dialogue between inside and outside perspectives, invite different levels of participation, develop both public and private community spaces, focus on value, combine familiarity and excitement, and create a rhythm for the community (p. 51). The guiding question for this study was, "How might a CVL exhibit aliveness and thus be conceived as a CoP within music courses?"

\section{Method}

I assigned CVL projects to students in seven courses at three large public universities in the Midwest United States, in which self-selected groups of four to seven students each posted on their assigned day of the week to have an asynchronous discussion. The project lasted four to 12 weeks depending on the course. Students were asked to fill out a one-page reflection on the project as their final assignment, and these reflections served as data. Each reflection included 11 questions about experiences throughout the project regarding the following topics: what vloggers would do the same and different if they were to do the project again; favorite and disliked aspects of the project; perceived educational implications; future plans for vlogging; suggestions for improving the project in the future; how the project affected their group dynamic; and assessment of themselves and their group members. While focusing on students' video products would have provided interesting data, written reflections offered an opportunity to understand students experiences firsthand, rather than collecting data through observing videos and then ascertaining what might have been going on in groups. Reflection responses were assigned a priori codes based on the seven principles of aliveness, and 2,382 points of interest were identified from the reflections. Data were analyzed by code and grouped (Emerson et al., 2011) to gain a better understanding of the presence or absence of each principal.

\section{Synopsis of Findings and Discussion}

Examples from all seven aliveness principles became apparent as CoPs formed in most CVL groups. The first principle, design for evolution, was exemplified through students' perceived freedom to choose topics of discussion, adapting technology and media to meet their needs, and an evolving self- and group-identity. Principle two, dialogue between inside and outside perspectives, was seen through how individual vloggers brought unique experiences representing their outside perspectives. Additionally, the relationships developed and conversations had within each CVL fostered an insider perspective through a camaraderie students demonstrated in their conversations online, which also extended to the classroom. Aliveness allowed for differing levels of participation (principle three) as students were able to choose how much energy and time they put into the project, as long as they fulfilled the requirement to post on their assigned day. Varying levels of participation allowed students to pursue the learning outcomes they wanted, which included but were not limited to technological, leadership, musical, and communication skills.

The fourth principle required students to consider the public and private spaces CVLS and the classroom afforded. Choices were given on whether to publish or privatize YouTube channels. Students also found that the technologies and physical spaces in which they collaborated influenced how they learned and created within their small 
groups. Students had to consider the values they found in the CVL process. Value, the fifth principle, was found for some in vlogging, technology, discussing, music, creativity, enjoyment, self-reflection, relationships, and learning. The sixth principle dealt with fostering familiarity and excitement. Attitudes toward CVLs evolved throught the projects' timelines. Students identified how CVLs, while unfamiliar, held aspects of familiarity—for example, YouTube, vlogging, and conversing with friends. Familiar aspects along with the novelty of trying something new with technology and getting a grade for participation led to excitement for learning. The final principle of developing a rhythm manifested within CVL groups, which allowed students—or perhaps required students-to experience a flow and momentum for learning and online content creation.

CVLs display promise as a versatile pedagogical tool that could be designed to suit the needs of almost any course or community, not just musical classrooms. By encouraging students to discuss important topics through asynchronous video posting, CVLs may exhibit the CoP principles of aliveness and flourish to help students learn, develop their own voices, and find a support system of collaborators.

\section{References}

Cayari, C., \& Fox, H. L. The pedagogical implications of the collaborative video log. 2013 Annual Proceedings: On the Practice of Educational Communications and Technology, 351-363.

Fox, H. L., \& Cayari, C. (2016). Graduate Students' Readiness and Perceptions of the Pedagogical Application of Collaborative Video Logs. TechTrends, 60(6), 585-590.

Hung, S.-T. (2011). Pedagogical applications of Vlogs: An investigation into ESP learners' perceptions. British Journal of Educational Technology, 42(5), 736-746.

Juhasz, A. (2008). Why not (to) teach on YouTube. In G. Lovink \& S. Niederer (Eds.), Video vortex reader: Responses to YouTube (pp. 133-140). Amsterdam, NL: Institute for Network Cultures.

Lin, C., \& Polaniecki, S. (2009). From media consumption to media production: Applications of YouTube in an eighth-grade video documentary project. Journal of Visual Literacy, 28(1), 92-97.

Waldron, J., \& Veblen, K. (2009). Learning in a Celtic community: An exploration of informal music learning and adult amateur musicians. Bulletin of the Council for Research in Music Education, (180), 59-74.

Wenger, E. (1998). Communities of practice: Learning, meaning, and identity. New York, NY: Cambridge University Press.

Wenger, E., McDermott, R. A., \& Snyder, W. (2002). Cultivating communities of practice: A guide to managing knowledge. Boston, MA: Harvard Business Press. 